\title{
Management of Postintubational Tracheal Injury by Endoscopic Stent Placement: Case Report and Review of the Literature
}

\author{
Christian Geltner ${ }^{1}$ Rudolf Likar ${ }^{2}$ Klaus Hausegger ${ }^{3}$ \\ ${ }^{1}$ Department of Pulmonology, Klinikum Klagenfurt, \\ Klagenfurt, Austria \\ ${ }^{2}$ Anesthesia and Intensive Care, Klinikum Klagenfurt, \\ Klagenfurt, Austria \\ ${ }^{3}$ Department of Radiology, Klinikum Klagenfurt, Klagenfurt, Austria
}

Markus Rauter ${ }^{1}$

\author{
Address for correspondence Christian Geltner, MD, MSc, MBA, \\ Pulmonology, Klinikum Klagenfurt-Feschnigstrasse 11, Klagenfurt \\ AT9020, Austria (e-mail: christian@geltner.at).
}

Thorac Cardiovasc Surg Rep 2016;5:8-12.

\begin{abstract}
Keywords

- bronchial disease

- tracheal injury

- stent

- anesthesia

- benign lesion

Endobronchial stent placement is a novel therapy for treatment of iatrogenic tracheal tears. A review of the available literature shows surgery and long-term intubation being the established treatment strategy.

We describe the case of a 64-year-old woman with a tracheal rupture following endotracheal intubation for routine surgery. Pneumo-mediastinum and chest pain were the predominant symptoms. She was treated with a covered self-expandable metal stent that closed the tear and led to immediate symptom relief. After six weeks and complete healing of the trachea, the stent could be explanted. No stent complications occurred. A new algorithm for the treatment of these ruptures has been proposed.
\end{abstract}

\section{Introduction}

Tracheal rupture or major tracheal injury is a rare condition mostly seen in cases of head and neck injury. Certain procedures also carry the risk of iatrogenic injury (intubation, tracheostomy, bronchoscopy, stent placement, esophagectomy, and others). Tracheal rupture is defined as complete circumferential injury of the trachea. Tears are longitudinal injuries of the trachea, both seen in orotracheal intubation especially in the emergency setting. This appears to be the most common cause. ${ }^{1,2}$

Orotracheal intubation is a routine procedure that nevertheless carries the potential for complications. Despite the large number of intubations performed every day, these complications fortunately are rare. They include throat pain, laryngitis, glottis edema, and mucosal ulceration, to laryngeal or tracheal stenosis, necrosis of the tracheal wall, fistulas, aspiration, esophageal intubation, bronchial intubation, atelectasis, and tracheal rupture. Some procedure-related risk factors have also been described which are as follows: multiple forced attempts, inexperience of the health professional, over inflation of the cuff, incorrect position of the tip of the tube, repositioning the tube without deflation of the cuff, inappropriate size of the tube, significant cough, and movements of the head and neck while the patient is intubated. ${ }^{3,4}$ Constitutional risk factors as congenital tracheal abnormalities, weakness of the pars membranous of the trachea, chronic obstructive pulmonary disease, diseases that alter the position of the trachea (mediastinal collections, lymph nodes, or tumors), chronic use of steroids, advanced age have been discussed. ${ }^{5}$ Most case reports refer to female patients above the age of 50 years. Chen et al. performed a literature review and defined an at-risk population that included women over 50 years of age who required intubation with double-lumen tubes and/or excessive pressure of the tube cuff.

The first case series was published in $1995 .{ }^{6}$ Post-intubational tracheal injury is a very rare disease and the suspected received

July 28, 2015

accepted after revision

November 16, 2015

published online

January 5, 2016
DOI http://dx.doi.org/

10.1055/s-0035-1570376. ISSN 2194-7635. (c) 2016 Georg Thieme Verlag KG
Stuttgart · New York

License terms

(c) $(1) \$$ 
incidence is approximately $1 / 20,000$ endotracheal intubations. ${ }^{7}$ More recently published cases and case series showed 0.05 to 0.15 cases per thousand intubation performed. ${ }^{8}$

Tracheal injury is suspected when signs of subcutaneous emphysema, chest pain, pneumothorax, or hemoptysis are present. In a clinical setting computer tomography is usually performed to rule out pulmonary embolism and other causes of acute chest pain. Diagnosis is confirmed by bronchoscopy which shows the size and location of tracheal injury. Bronchoscopy is also essential to plan further treatment options and helps to guide endo-tracheal tubes. The treatment of choice has traditionally been urgent surgical repair, though a recent review of the literature advocates conservative treatment. ${ }^{2}$ In a metaanalysis including 181 patients, $61 \%$ were treated with tracheal surgery whereas $39 \%$ underwent a conservative approach with prolonged tracheal intubation and ventilation. All patients diagnosed with intra-operatively were treated surgically. Overall mortality was approximately $22 \%$. Some series have demonstrated an extremely high mortality rate, especially in critically ill patients with tracheal injury and following intraoperative surgical repair. Because of the high intra- and postoperative mortality, the conservative approach was favored. Marquette et al demonstrated a case of tracheal rupture with spontaneous healing as soon as positive-pressure ventilation was not applied. ${ }^{9}$

A group from Taiwan ${ }^{10}$ published a treatment algorithm based on the review of several case reports in 2004 and a previously designed approach by Jougon et al. ${ }^{11}$ The authors proposed an algorithm for the treatment of post intubation tracheobronchial rupture and suggested surgical repair for patients with immediate symptoms. Surgery is decided when the length of the tear is longer than $4 \mathrm{~cm}$, otherwise a conservative management is favored. ${ }^{12}$

As novel treatment option endotracheal stent placement has been described in a few case reports. ${ }^{13}$ This option of a non-surgical approach with an endo-bronchial interventional technique is simple to perform and gives reasonable results without the complications of major thoracic surgery. Only few case reports are available and in most reviews and published algorithms, this technique has not been even mentioned. We present a case of successful stent placement and healing of an iatrogenic tracheal injury.

\section{Case Report}

A 64-year-old woman underwent elective surgery for total knee endoprothesis at an orthopedic surgical department. General anesthesia was routinely performed and the patient was intubated with a normal $8 \mathrm{~mm}$ endotracheal tube. The patient had no underlying pulmonary or cardiac disease, no history of smoking and normal routine blood parameters. The elective surgery was performed without complications. She received apixaban for antithrombotic prophylaxis and was transferred to the normal ward. Six hours after extubation, the patient developed chest pain and dyspnea. ECG and Chest $\mathrm{X}$-ray reports were found to be normal. D-dimer was slightly elevated so chest CT for exclusion of pulmonary embolism was performed. Oxygenation and hemodynamic were normal. Chest CT showed no signs of embolism, no consolidations, no pneumothorax. CT scan revealed pneumo-mediastinum and tracheal injury (-Fig. 1). The patient was then referred to our pulmonary department for bronchoscopic evaluation and further treatment. She was stable without signs of cardiopulmonary impairment but was monitored during transfer and waiting time for the endoscopic procedure. As the tracheal tear had already been diagnosed before, the patient was intubated by a rigid tracheoscope in general anesthesia. The tracheal tear started at the middle part of the trachea and continued till $1 \mathrm{~cm}$ above the carina (-Fig. 2a). The length of the tear was approximately $5 \mathrm{~cm}$. The bronchial system below the tracheal injury was normal without signs of other injuries.

Stent placement was performed under visual control by rigid and flexible bronchoscope. Intubation for bronchoscopies was done routinely with a rigid bronchoscope (Storz, Germany) and jet ventilation at our institution. A covered self-expandable metal stent was placed (Alveolus Air stent, United States) under additional fluoroscopic control. Stent position could be controlled by the aid of a small flexible bronchoscope through the working channel of the positioning system. It was possible to place the stent over the complete fissure and injury area. After deployment of the endotracheal stent, the fissure was completely closed and the outer diameter made a complete wall adhesion to the tracheal wall. (-Fig. 3 )

The patient was shifted to our standard care ward for overnight surveillance and did not develop any further complications. The next day, Routine bronchoscopic control showed an ideal position of the stent. A CT scan for evaluation of pneumomediastinum and pneumothorax was performed and revealed complete absorption of air and a complete closure of the tracheal tear. (-Fig. 2b) The patient could be dismissed and was readmitted 6 weeks later for bronchoscopic stent removal. The trachea had healed completely and did not show any granulation tissue or other stent complications.

\section{Discussion}

Tracheobronchial stents have long been used in the management of airway obstruction in both malignant and benign diseases $^{14}$ with excellent short-term symptomatic relief. Severe long-term complications as granulation tissue, stent migration, infection, and chronic cough shorten the use in benign conditions ${ }^{15-17}$

Postintubational tracheal injury is a very rare condition and we therefore do not have adequate prospective studies to evaluate its incidence. Consensus on the best treatment options has not yet been agreed upon. Early surgery has been favored for large tears with progression of symptoms and need for mechanical ventilation. Treatment of tracheal tears was recommended by major surgery especially in cases of previous thoracic surgery intra-operatively because of easy accession to the lesion. ${ }^{18}$ Some case series and a metaanalysis performed by Minambres et al in 2009 suggested that there is more evidence for supporting conservative management by observation, intubation, and cuffing by the endotracheal tube and mechanical ventilation with restricted inspiratory pressure. 2,19 


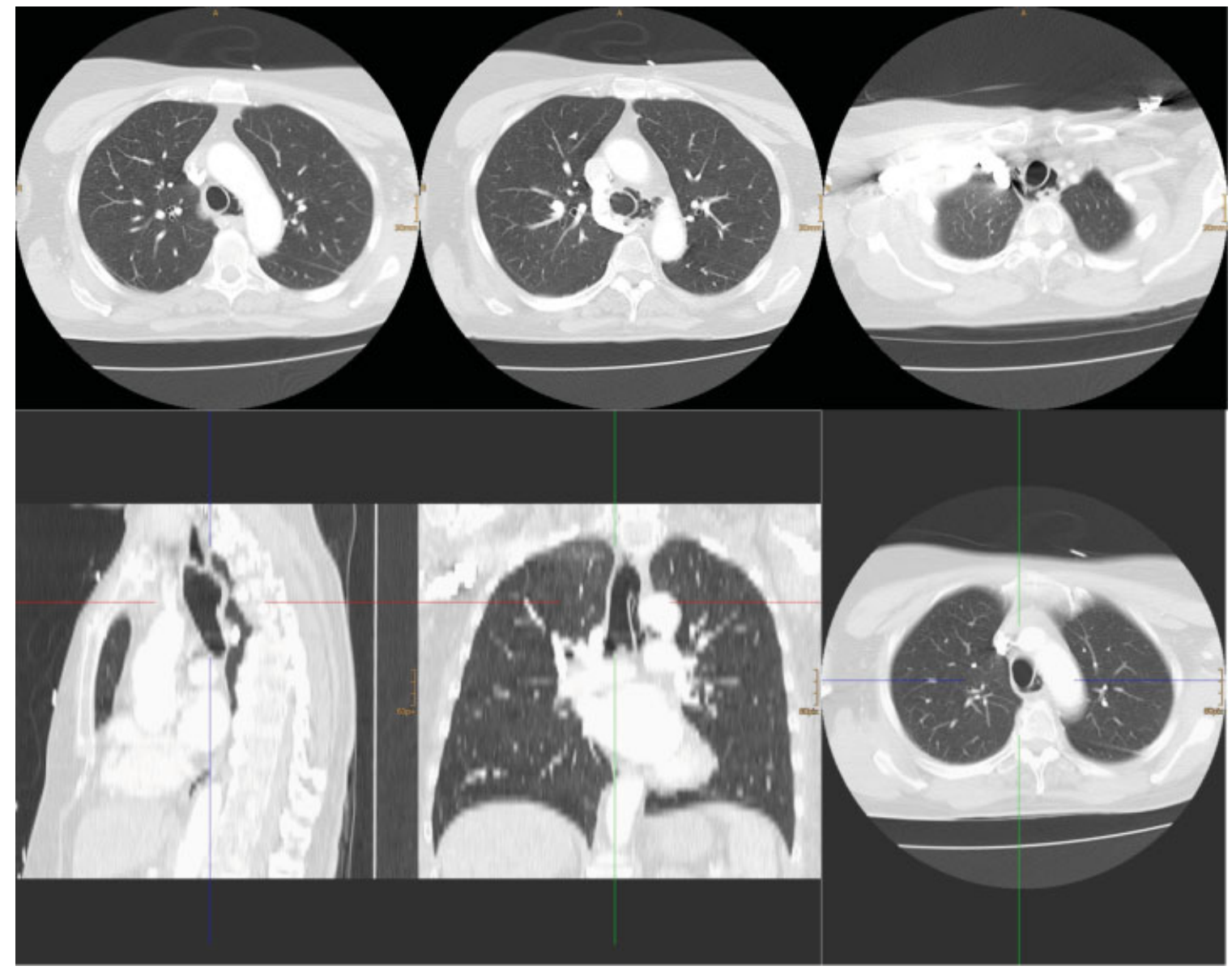

Fig. 1 Pneumomediastinum and tracheal rupture after routine endobronchial intubation. CT-scans with coronary and sagittal reconstruction.

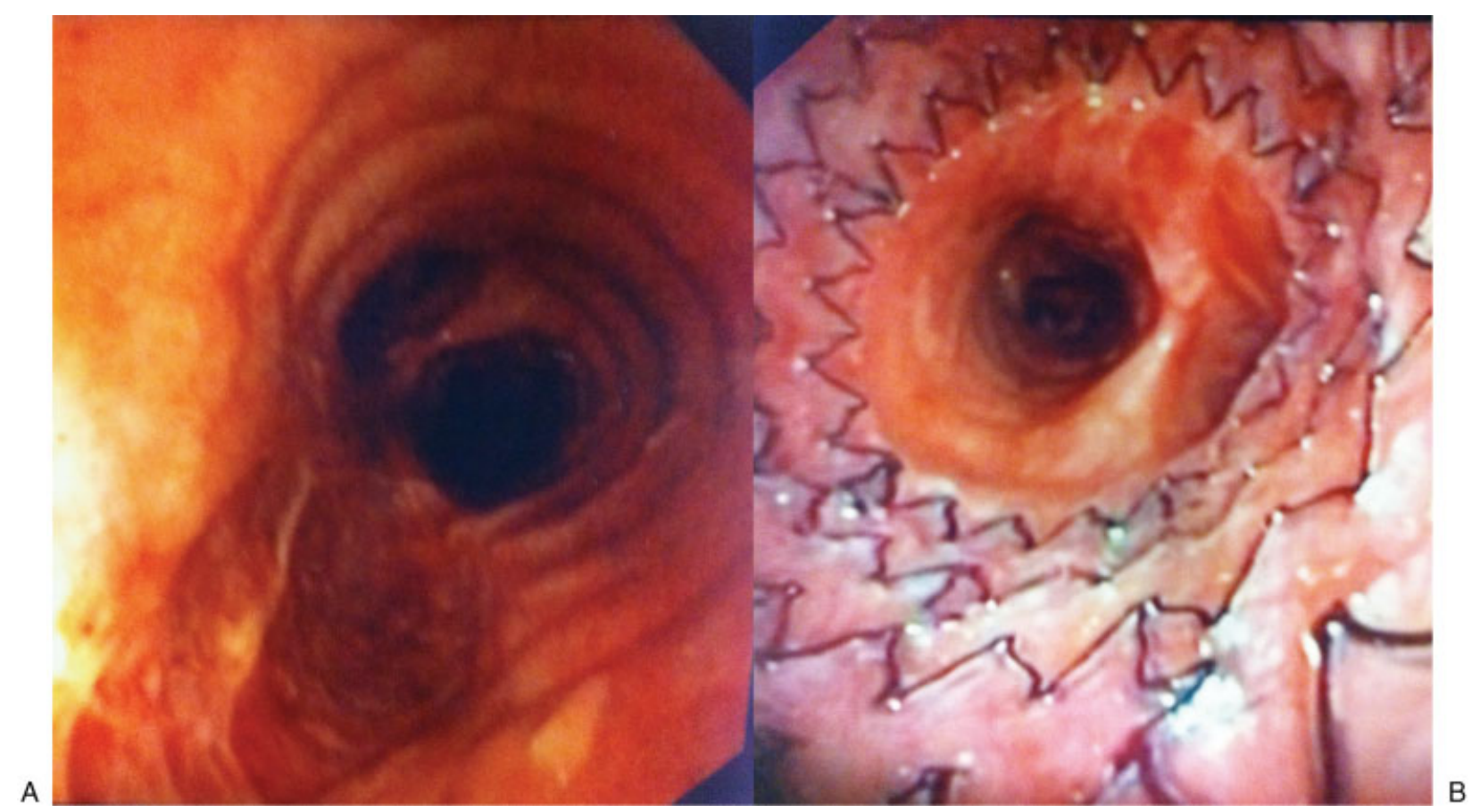

Fig. 2 (A, B) Tracheal injury in the distal tracheal part with a $4 \mathrm{~cm}$ long tracheal tear and bronchoscopic imaging after stent placement (ALVEOLUS tracheal stent). 


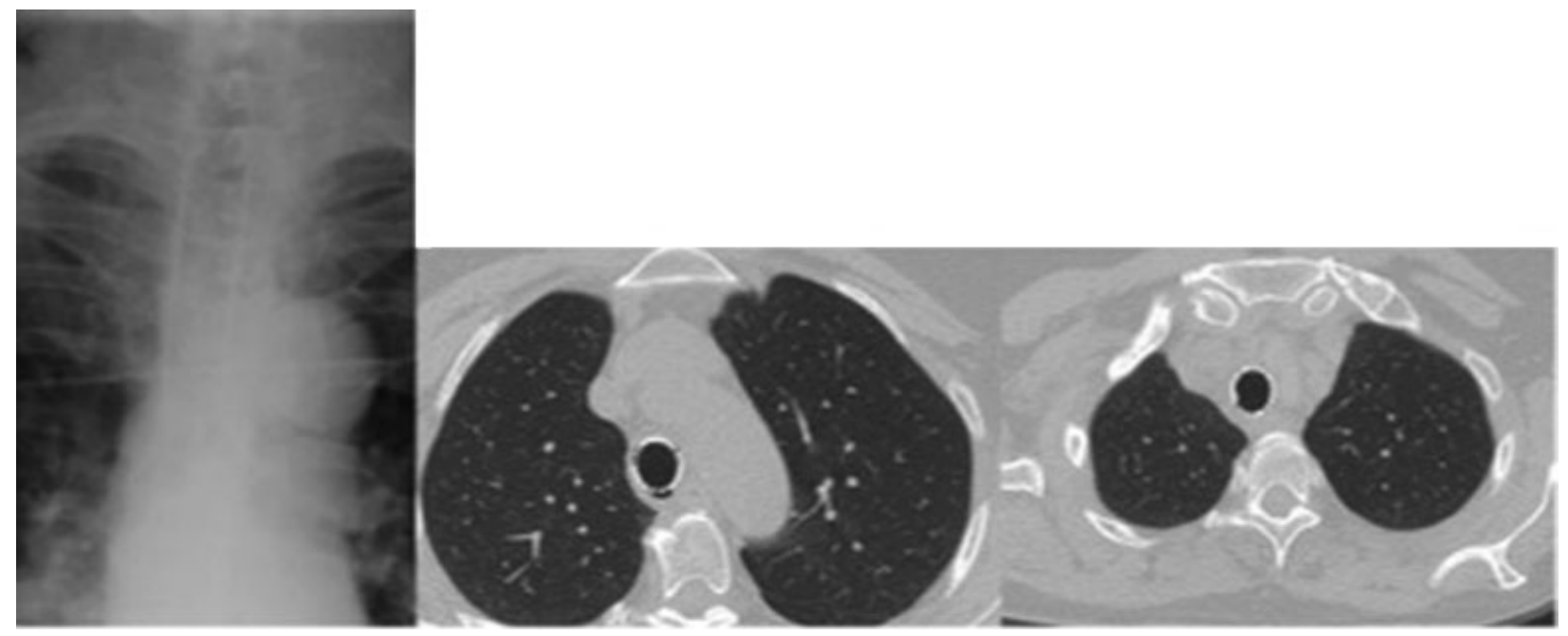

Fig. 3 Chest X-ray and CT-scan after successful endotracheal stent placement.

Most available guidelines are based on algorithms for surgical versus conservative treatment. Supported by some case reports and a proposed algorithm by Yopp et al ${ }^{13}$ tracheal stenting was a feasible therapeutic option. In our case, it was much easier to treat the patient's injury by stenting as the tear was below the first third of the trachea and did not exceed the main carina. A surgical approach was dismissed because of its potential risks.
We believe that tracheal stenting is a useful therapy for large tracheal injury and a valid alternative in patients precluded from surgical reconstruction with a comparatively high rate of perioperative morbidity and mortality. Stent placement is a simple and secure procedure that supports an early healing of the tears. Stent explantation should be considered six weeks after placement as the risk for occurrence of granulation tissue rises after 3 months. Iatrogenic tracheobronchial tears have

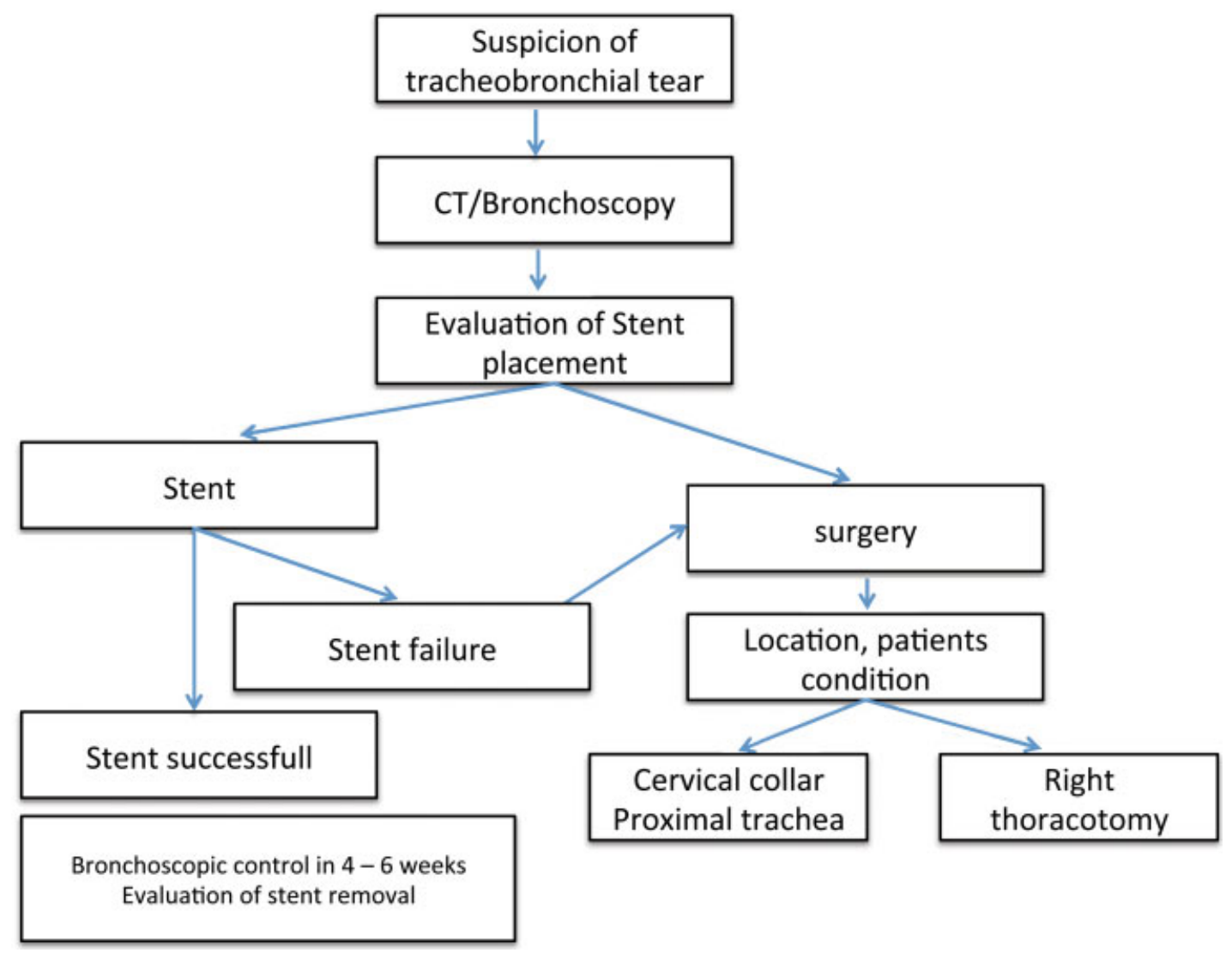

Fig. 4 Algorithm for management of iatrogenic tracheal injury adapted from Yopp et al $2007^{13}$ and Fan et al $2004 .^{10}$ 
typically been handled conservatively in patients with small tears ( $<2 \mathrm{~cm}$ in length) or those without progressive worsening mediastinal or subcutaneous emphysema. ${ }^{20}$ Larger tears ( $>4 \mathrm{~cm}$ ) were traditionally managed surgically. For all lesions between 2 and $4 \mathrm{~cm}$ in length a variety of approaches have been reported by different authors and the applied technique was decided individually and depending on the availability of different therapeutic options.

The specific surgical approach depends on the location of tracheal injury: lesions found in the proximal two thirds of the trachea are approached by a cervical collar incision, more distal ones by a right anterior thoracotomy. ${ }^{20,21}$

This treatment algorithm can be adapted, in both situations, the early treatment of the tear by stenting provides increment of mediastinal or subcutaneous emphysema and probably the occurrence of mediastinitis (- Fig. 4) ${ }^{20}$ To date, the question as to which technique can prevent mediastinitis cannot be sufficiently answered from the available literature and data. The exact incidence rate of mediastinitis is not known and can only be estimated. There are several reports of mediastinitis complicating esophageal rupture, fistulae and stents but no cases of mediastinitis complicating airway stents. Antibiotic treatment seems to be indicated in any procedure with open access of the mediastinal tissue to the normal bacterial colonization of the tracheobronchial system.

Stent indication should be limited to injuries with the possibility of complete closure by the device and sufficient distance from the larynx for patient's comfort and avoiding complication. A combined stenting of the distal trachea and the main stem bronchi is possible with Y-stents. There is no difference in the occurrence of stent complications.

Limitations to this therapeutic approach are known stent complications including stent migration, mucostasis, halitosis and granulation tissue development. With the use of completely covered (newer) tracheal stents or silicon stents, these problems decrease as has been reported in patients with other indications for tracheobronchial stents. In case of early stent-failure, a progression to any other treatment option is possible (see the proposed treatment algorithm).

\section{Conclusion}

This case report shows the feasibility of endoscopic stent placement in the emergency treatment of tracheal injuries. In our case, an iatrogenic tracheal tear was treated by endotracheal stent placement which was left in place for six weeks. There were no complications to report. Stenting is a successful treatment option for tracheal tears and has no severe complications.

\section{Conflict of Interest}

The authors do not claim any conflict of interest concerning this case report.

\section{Acknowledgment}

The authors thank Prof. Gilles Vince for the excellent correction and linguistic improvement of the manuscript.

\section{References}

1 Berry M, Van Schil P, Van Meerbeeck J, Vanmaele R, Eyskens E. Surgical treatment of iatrogenic tracheal lacerations. Acta Chir Belg 1997;97(6):308-310

2 Miñambres E, Burón J, Ballesteros MA, Llorca J, Muñoz P, GonzálezCastro A. Tracheal rupture after endotracheal intubation: a literature systematic review. Eur J Cardiothorac Surg 2009;35(6): 1056-1062

3 Evagelopoulos N, Tossios P, Wanke W, Krian A. Tracheobronchial rupture after emergency intubation. Thorac Cardiovasc Surg 1999; 47(6):395-397

4 Chen EH, Logman ZM, Glass PS, Bilfinger TV. A case of tracheal injury after emergent endotracheal intubation: a review of the literature and causalities. Anesth Analg 2001;93(5): $1270-1271$

5 Wagner A, Roeggla M, Hirschl MM, Roeggla G, Schreiber W, Sterz F. Tracheal rupture after emergency intubation during cardiopulmonary resuscitation. Resuscitation 1995;30(3):263-266

6 Marty-Ané CH, Picard E, Jonquet O, Mary H. Membranous tracheal rupture after endotracheal intubation. Ann Thorac Surg 1995; 60(5):1367-1371

7 Orta DA, Cousar JE III, Yergin BM, Olsen GN. Tracheal laceration with massive subcutaneous emphysema: a rare complication of endotracheal intubation. Thorax 1979;34(5):665-669

8 Borasio P, Ardissone F, Chiampo G. Post-intubation tracheal rupture. A report on ten cases. Eur J Cardiothorac Surg 1997;12(1): 98-100

9 Marquette $\mathrm{CH}$, Bocquillon N, Roumilhac D, Nevière R, Mathieu D, Ramon P. Conservative treatment of tracheal rupture. J Thorac Cardiovasc Surg 1999;117(2):399-401

10 Fan CM, Ko PC, Tsai KC, et al. Tracheal rupture complicating emergent endotracheal intubation. Am J Emerg Med 2004; 22(4):289-293

11 Jougon J, Ballester M, Choukroun E, Dubrez J, Reboul G, Velly JF. Conservative treatment for postintubation tracheobronchial rupture. Ann Thorac Surg 2000;69(1):216-220

12 Harris R, Joseph A. Acute tracheal rupture related to endotracheal intubation: case report. J Emerg Med 2000;18(1):35-39

13 Yopp AC, Eckstein JG, Savel RH, Abrol S. Tracheal stenting of iatrogenic tracheal injury: a novel management approach. Ann Thorac Surg 2007;83(5):1897-1899

14 Madden BP, Loke TK, Sheth AC. Do expandable metallic airway stents have a role in the management of patients with benign tracheobronchial disease? Ann Thorac Surg 2006;82(1): 274-278

15 Saad CP, Murthy S, Krizmanich G, Mehta AC. Self-expandable metallic airway stents and flexible bronchoscopy: long-term outcomes analysis. Chest 2003;124(5):1993-1999

16 Noppen M, Stratakos G, D'Haese J, Meysman M, Vinken W. Removal of covered self-expandable metallic airway stents in benign disorders: indications, technique, and outcomes. Chest 2005;127(2):482-487

17 Gildea TR, Murthy SC, Sahoo D, Mason DP, Mehta AC. Performance of a self-expanding silicone stent in palliation of benign airway conditions. Chest 2006;130(5):1419-1423

18 Conti M, Pougeoise M, Wurtz A, et al. Management of postintubation tracheobronchial ruptures. Chest 2006;130(2): 412-418

19 Beiderlinden M, Adamzik M, Peters J. Conservative treatment of tracheal injuries. Anesth Analg 2005;100(1):210-214

20 Mussi A, Ambrogi MC, Menconi G, Ribechini A, Angeletti CA. Surgical approaches to membranous tracheal wall lacerations. J Thorac Cardiovasc Surg 2000;120(1):115-118

21 Ambrogi MC, Mussi A, Ribechini A, Angeletti CA. Posterior wall laceration of the thoracic trachea: the transcervicaltranstracheal approach. Eur J Cardiothorac Surg 2001;19(6): 932-934 